20

\title{
Спонтанное и вынужденное комбинационное рассеяние света в протиевой и дейтериевой воде *
}

\author{
(C) B.C. Горелик ${ }^{1,2}$, Dongxие Bi ${ }^{2}$, Ю.П. Войнов ${ }^{1}$, А.И. Водчиц ${ }^{3}$, В.А. Орлович ${ }^{3}$, А.И. Савельева ${ }^{2}$ \\ ${ }^{1}$ Физический институт им. П.Н. Лебедева РАН, \\ 119991 Москва, Россия \\ ${ }^{2}$ Московский государственный технический университет им. Н.Э. Баумана, \\ 105005 Москва, Россия \\ ${ }^{3}$ Институт фризики им. Б.И. Степанова НАН Беларуси, \\ 220072 Минск, Беларусь \\ e-mail: gorelik@sci.lebedev.ru
}

Поступила в Редакцию 20.11.2018 г.

В окончательной редакции 12.02.2019 г.

Принята к публикации 12.02.2019 г.

\begin{abstract}
Выполнено сопоставление спектров комбинационного рассеяния для различных проб протиевой и дейтериевой воды. Регистрация спектров была проведена с использованием волоконно-оптической методики и малогабаритного спектрометра BWS465-785H. Возбуждение спектров спонтанного комбинационного рассеяния осуществлялось с помощью непрерывного лазера с длиной волны $785 \mathrm{~nm}$. Наблюдались существенные различия низкочастотных спектров комбинационного рассеяния от разных проб воды, объясняемые присутствием структурных изменений и примесей в анализируемых пробах. Зарегистрированы спектры вынужденного комбинационного рассеяния в протиевой и дейтериевой воде при возбуждении пикосекундными лазерными импульсами с длиной волны $532 \mathrm{~nm}$. Обнаружено наличие низкочастотных спутников в спектре вынужденного комбинационного рассеяния, свидетельствующих о структурировании воды, обусловленном формированием кластеров, состоящих из нескольких молекул.
\end{abstract}

DOI: $10.21883 /$ OS.2019.06.47771.51-19

\section{Введение}

Вода является важным компонентом биосферы, структура и молекулярный состав которого играют большую роль в процессах жизнедеятельности биообъектов. Молекулярная структура воды обусловлена строением ее молекул, а также формированием так называемого дальнего порядка, приводящего к образованию микрокластеров и пространственно организованной „сетки“ [1-5]. При введении в воду различных объектов в виде растворенных компонентов или частиц, находящихся во взвешенном состоянии, молекулярная структура воды может существенно видоизменяться [6]. Изменение структуры непосредственно отражается на качестве воды, что, в свою очередь, может приводить к различным дисфункциям в живых организмах [7]. Изучение свойств и тестирование качества воды является необходимым условием для нормального здорового существования.

Эффективными средствами анализа молекулярного состава и структуры являются оптические методы, в частности спектроскопия спонтанного и вынужденного комбинационного рассеяния [8-11]. Особый интерес для биосферы представляет дейтериевая вода $\left(\mathrm{D}_{2} \mathrm{O}\right)$, присут-

\footnotetext{
* The 22nd Annual Conference Saratov Fall Meeting 2018 (SFM'18): VI International Symposium „Optics and Biophotonics“ and XXII International School for Junior Scientists and Students on Optics, Laser Physics \& Biophotonics, September 24-29, 2018, Saratov, Russia. https://www.sgu.ru/structure/fiz/saratov-fall-meeting/previousconferences/saratov-fall-meeting-2018
}

ствие которой в организмах приводит к существенным изменениям процессов метаболизма, подавлению ферментативных реакций и клеточного роста [12]. Дейтериевая вода применяется в качестве изотопного индикатора в химии и биологии, а также для обнаружения нейтронов в астрофизике и физике элементарных частиц. Такая вода обладает способностью замедления скорости нейтронных пучков, что имеет большое значение для реализации процессов термоядерного синтеза. Присутствие дейтериевой воды устанавливается в результате анализа соответствующих спектров спонтанного комбинационного рассеяния (СКР) [13]. Новые возможности для исследования физических свойств воды открываются при наблюдении процессов вынужденного комбинационного рассеяния (ВКР) в протиевой и дейтериевой воде.

Ранее спектры СКР в воде изучались в работах [14-18]. При этом исследовалась главным образом область высоких частот $\left(2800-3500 \mathrm{~cm}^{-1}\right)$. В работах [11,19-22] были обнаружены также комбинационные полосы, соответствующие кластерным модам: трансляциям и либрациям молекул протиевой воды. ВКР в протиевой воде изучалось в работе [23]. При этом анализировались спектры в области высокочастотной полносимметричной моды с частотой $3300 \mathrm{~cm}^{-1}$. Спектры поглощения в дейтериевой воде исследовались в работе [24] в диапазоне частот $4000-8000 \mathrm{~cm}^{-1}$. При этом обнаружились полосы, соответствующие обертонным переходам молекулы $\mathrm{D}_{2} \mathrm{O}$. В работе [25] исследовалось 
BКР в $\mathrm{D}_{2} \mathrm{O}$ при возбуждении наносекундными импульсами второй оптической гармоники лазера $\mathrm{Nd}$ :YAG. При этом конкурирующим с процессом ВКР является вынужденное рассеяние Мандельштама-Бриллюэна. Возбуждение ВКР в дейтериевой воде пикосекундными лазерными импульсами было выполнено в работе [26]. При этом длительность импульсов возбуждающего излучения составляла 5-6 ps. Вследствие малой длительности таких импульсов и самофокусировки излучения наблюдаемый спектр ВКР имел вид континуума со слабо выраженным пиком интенсивности на частоте полносимметричного валентного колебания.

В настоящей работе ставилась задача исследования закономерностей в спектрах СКР и ВКР в протиевой и дейтериевой воде в широкой области спектра, включая низкочастотный диапазон. ВКР в протиевой и дейтериевой воде наблюдалось при возбуждении лазерными импульсами длительностью 60 ps, т.е. на порядок превышающими длительность импульсов, используемых в работе [26]. Это обеспечило отсутствие континуализации наблюдаемых спектров вследствие увеличения длительности возбуждающих импульсов по сравнению с работой [26] в соответствии с соотношением неопределенности для энергии-времени.

\section{Методика эксперимента}

В качестве объектов исследования нами были выбраны различные пробы протиевой и дейтериевой воды: водопроводная вода, бутилированная вода типа „Шишкин Лес“ и вода, отфильтрованная с помощью фильтра „Аквафор Модерн“. Проба дейтериевой воды в соответствии с паспортом изготовителя содержала 99\% $\mathrm{D}_{2} \mathrm{O}$ и $1 \% \mathrm{H}_{2} \mathrm{O}$. Проба воды „Шишкин Лес“ является артезианской водой $\mathrm{H}_{2} \mathrm{O}$. Для регистрации спектров СКР использовался полупроводниковый лазер с длиной волны $785 \mathrm{~nm}$ со средней мощностью до $420 \mathrm{~mW}$ (рис. 1). Анализ спектров СКР в воде проводился с использованием малогабаритного волоконно-оптического спектрометра типа BWS465-785H. Возбуждающее и рассеянное излучение передавалось волоконно-оптической системой к образцу и к детектору сигнала СКР (многоэлементному приемнику).

Для возбуждения ВКР в воде использовалась вторая оптическая гармоника лазера YAG: $\mathrm{Nd}^{3+}$ с длиной волны генерации $\lambda=532 \mathrm{~nm}$. Такой лазер обеспечивал генерацию в импульсно-периодическом режиме сверхкоротких импульсов $(60 \mathrm{ps})$ с частотой повторений $100 \mathrm{~Hz}$ при средней мощности 10-100 mW. Принципиальная схема для исследования ВКР в протиевой и дейтеривой воде приведена на рис. 2.

При этом импульсное лазерное излучение фокусировалось с помощью линзы 3 в кювете с водой, помещаемой в дополнительный резонатор, формируемый диэлектрическими зеркалами 4, 6. Регистрация спектров ВКР осуществлялась для геометрий рассеяния „Вперед“

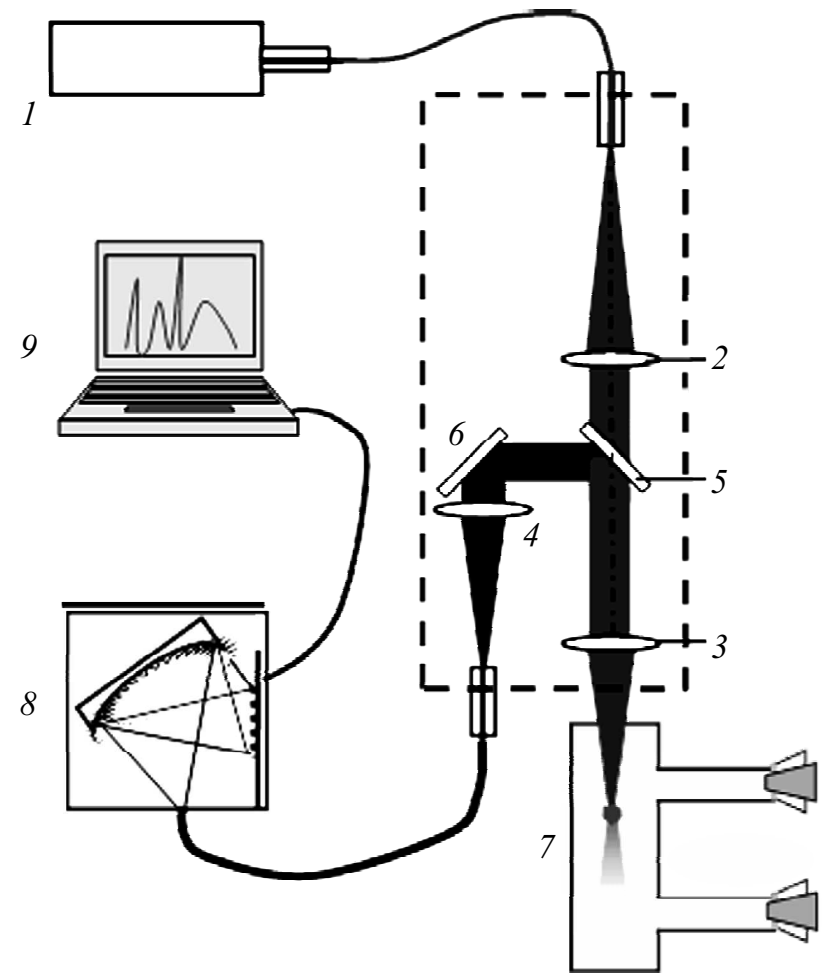

Рис. 1. Схема экспериментальной установки для регистрации спектров СКР в воде; 1 - лазерный источник излучения, 2-4 - линзы, 5, 6 - интерференционные фильтры, 7 анализируемый образец, 8 - миниспектрометр BWS465-785H, 9 - компьютер.

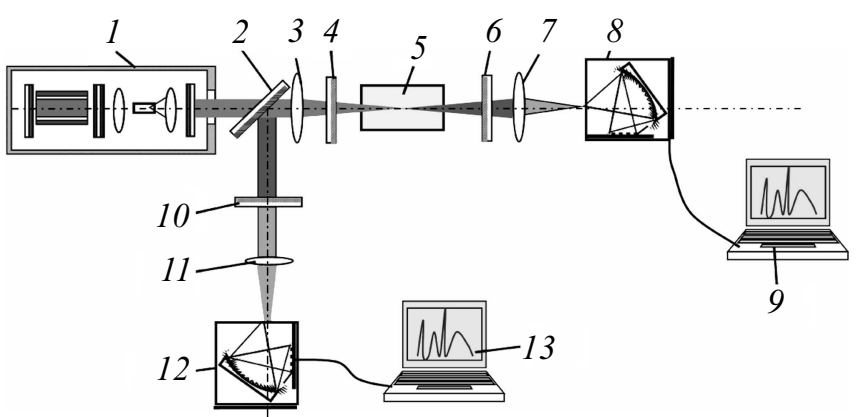

Рис. 2. Схема экспериментальной установки для регистрации спектров ВКР в воде; 1 - лазерный источник излучения, 2 - поворотное диэлектрическое зеркало, 3, 7,11 - линзы, 4,6,10 - диэлектрические зеркала, 5 - кювета с водой, 8,12 - спектрометры, 9,13 - компьютеры.

и „назад“ волоконно-оптическими миниспектрометрами 8,12 , обеспечивающими возможность анализа спектров в широком спектральном диапазоне: 200-1000 nm.

\section{Результаты и их обсужждение}

Известно [22], что в спектре СКР воды присутствуют полосы, соответствующие трем фундаментальным типам колебаний молекулы $\mathrm{H}_{2} \mathrm{O}$ : $A_{1}$-тип, $v_{1}=3450 \mathrm{~cm}^{-1}$ 

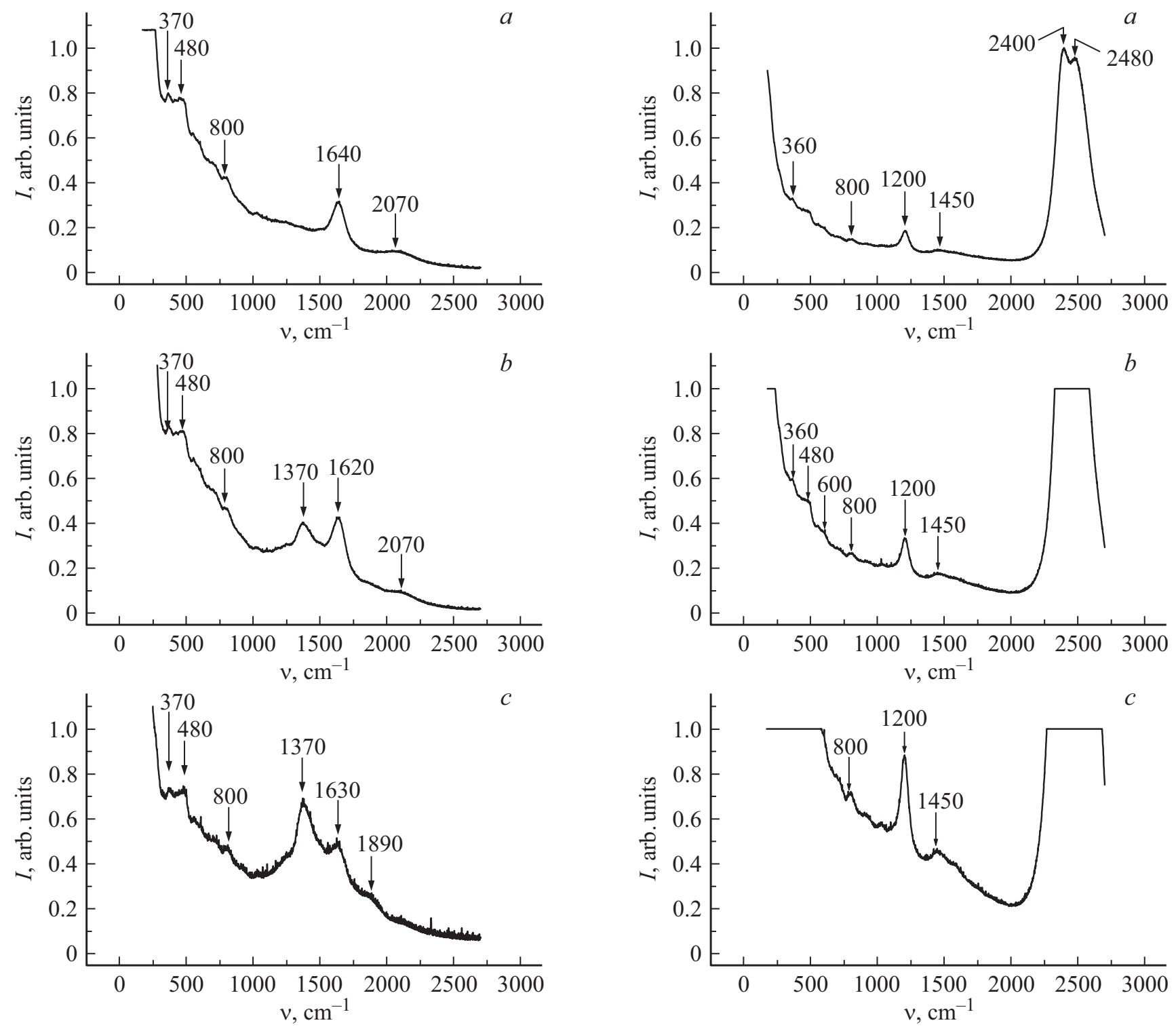

Рис. 3. Вид спектров СКР $(\lambda=785 \mathrm{~nm})$ протиевой воды в трех различных пробах $(a-c)$.

(валентное полносимметричное колебание), $A_{1}$-тип, $v_{2}=1645 \mathrm{~cm}^{-1}$ (деформационное полносимметричное колебание) и $B_{1}$-тип, $\nu_{3}=3630 \mathrm{~cm}^{-1}$ (валентное неполносимметричное колебание). На рис. $3, a-c$ представлены спектры СКР в области частот внешних мод и фундаментального колебания типа $v_{1}\left(A_{1}\right)$ для нескольких проб протиевой воды.

Как видно из сравнения рис. 3, $a-c$, в области колебания типа $v_{2}\left(A_{1}\right)$ (полносимметричная деформационная мода) на приведенных спектрах трех проб воды наблюдаются существенные различия. На рис. $3, a$ в этой области присутствует одиночная полоса, в то время как на рис. $3, b, c$ наблюдаются две полосы с различными распределениями интенсивности. Кроме того, на всех рис. 3, $a-c$ обнаруживается несколько перекрывающихся полос в области низкочастотного релаксационного

крыла, свидетельствующие о проявлении либрационных мод, обусловленных формированием молекулярных образований (кластеров) [27] в различных пробах воды. В высокочастотной области СКР протиевой воды присутствуют полосы, соответствующие двум типам валентных колебаний: $v_{2}\left(A_{1}\right)$ (полносимметричная валентная мода) и $v_{3}\left(B_{1}\right)$ (антисимметричная валентная мода).

На рис. 4, $a-c$ приведены спектры СКР в одной пробе дейтериевой воды при различных режимах регистрации спектрометра. Из этих рисунков видно, что в спектрах СКР дейтериевой воды обнаруживаются три фундаментальные полосы $v_{1}\left(A_{1}\right), v_{2}\left(A_{1}\right)$ и $v_{3}\left(B_{1}\right)$, а также дополнительная структура в низкочастотной области, соответствующая проявлению кластерных либрационных мод и составных тонов вблизи $v_{1}\left(A_{1}\right)$. Частоты фундаментальных колебаний в спектре СКР дейтерие- 

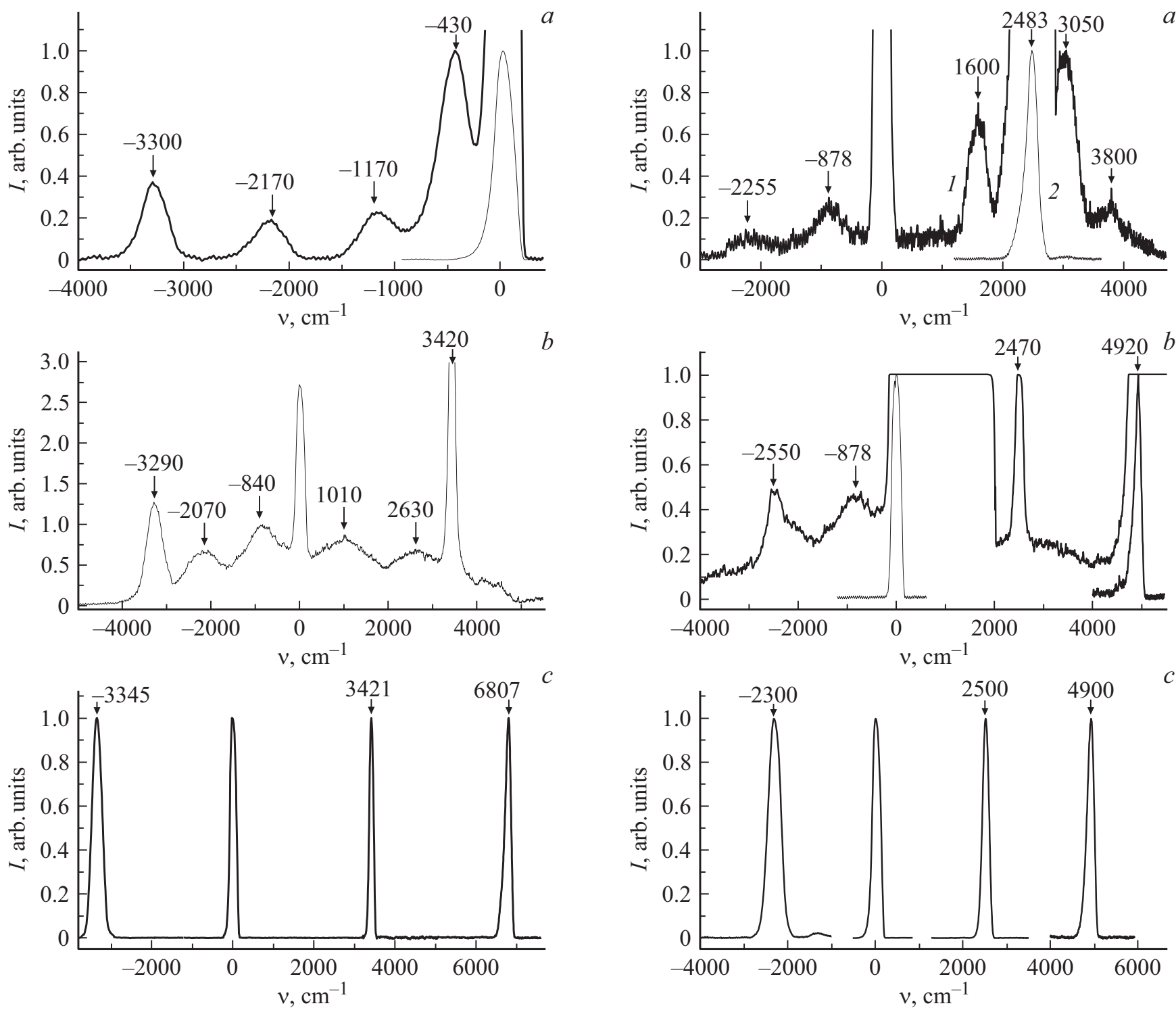

Рис. 5. Вид спектров ВКР в протиевой воде при различных интенсивностях лазерной накачки $(\lambda=532 \mathrm{~nm}): a-$ $I_{0}=5$ rel. units, $b-I_{0}=1$ rel. units, $c-$ нормированные спектры стоксова и антистоксова ВКР в протиевой воде при интенсивности накачки $I_{0}=20$ rel. units.

вой воды существенно меньше соответствующих частот компонент СКР протиевой воды, поскольку дейтерий тяжелее водорода, и соответствующие колебания ниже по частоте.

На рис. 5 и 6 приведены спектры ВКР в протиевой и дейтериевой воде соответственно. В протиевой воде в спектре ВКР обнаруживается несколько антистоксовых компонент (рис. 5, $a$ ), низкочастотные стоксовы и антистоксовы компоненты (рис. $5, b$ ) и несколько высокочастотных стоксовых компонент, наблюдаемых при большой интенсивности накачки (рис. 5,c). В случае дейтериевой воды также наблюдается несколько стоксовых и антистоксовых компонент (рис. $6, a-c$ ), частоты

которых существенно ниже соответствующих спутников в спектре ВКР протиевой воды.

Многочастотное ВКР осуществляется в результате распада двух квантов возбуждающего излучения на соответствующие стоксовы и антистоксовы компоненты. В этом случае законы сохранения энергии и квазимпульса приобретают вид

$$
\begin{array}{ll}
2 \omega_{L}=\omega_{1 S}+\omega_{1 A}, & 2 \mathbf{k}_{L}=2 \mathbf{k}_{1 S}+\mathbf{k}_{1 A} ; \\
2 \omega_{L}=\omega_{2 S}+\omega_{2 A}, & 2 \mathbf{k}_{L}=2 \mathbf{k}_{2 S}+\mathbf{k}_{2 A} ; \\
2 \omega_{L}=\omega_{3 S}+\omega_{3 A}, & 2 \mathbf{k}_{L}=2 \mathbf{k}_{3 S}+\mathbf{k}_{3 A} .
\end{array}
$$


В наблюдаемых спектрах ВКР присутствуют два стоксовых спутника и один антистоксов спутник (рис. 5,c и $6, c)$. Отметим также, что, кроме основных частот, соответствующих фундаментальной моде $v_{1}\left(A_{1}\right)$, в спектрах ВКР присутствуют также линии, обусловленные низкочастотными оптическими модами. Таким образом, в отличие от типичных спектров ВКР в спектре ВКР воды при достаточно большой интенсивности возбуждающего лазерного излучения присутствуют спутники, соответствующие различным типам колебаний, а также проявляются четырехфотонные параметрические процессы.

\section{Заключение}

Таким образом, установлено, что спектры СКР различных проб воды имеют существенные отличия. Это свидетельствует о наличии примесей и структурных изменений в реальных пробах воды.

Спектры многочастотного ВКР, наблюдаемого при воздействии пикосекундными импульсами, зависят от режима возбуждения. При этом обнаруживаются стоксовы и антистоксовы спутники, соответствующие фундаментальной полносимметричной моде $v_{2}\left(A_{1}\right)$.

Установлено, что в спектрах как СКР, так и ВКР протиевой и дейтериевой воды проявляются как внутримолекулярные моды молекул воды, так и моды микрокластеров, соответствующие трансляционным и либрационным движениям. Присутствие микрокластерных мод в спектре СКР воды свидетельствует о формировании при определенных условиях квазикристаллической сетки микрокластеров и может служить средством установления степени структурирования воды. Спектры СКР могут быть использованы для диагностики чистоты воды и степени ее структурирования.

Присутствие в спектрах ВКР воды низкочастотных спутников, соответствующих трансляционным и либрационным модам, представляет интерес для фотостимулированного структурирования воды и повышения таким образом степени усвоения протиевой воды организмами.

При наносекундном лазерном возбуждении ВКР в воде формируются когерентные трансляционные и либрационные волны квазикристаллической сетки, а также внутримолекулярные осцилляции ионов в молекулах $\mathrm{H}_{2} \mathrm{O}$ или $\mathrm{D}_{2} \mathrm{O}$ большой амплитуды.

При пикосекундном возбуждении ВКР в дейтериевой воде интенсивными лазерными импульсами видимого диапазона формируются ударные волны, соответствующие валентной полносимметричной моде, при сохранении температуры других степеней свободы вблизи равновесных значений.

\section{Финансирование работы}

Работа выполнена при поддержке РФФИ (гранты № 18-02-00181, 18-32-00259) и China Scholarship Council.

\section{Список литературы}

[1] Захаров С.Д., Мосягина И.В. Препринт. М.: Физ. ин-т им. П.Н. Лебедева, 2011. 24 с.

[2] Волошин В.П., Желиговская Е.А., Маленков Г.Г., Наберухин Ю.И., Тытик Д.Л. // Журн. Рос. хим. об-ва им. Д.И. Менделеева. 2001. Т. 45. № 3. С. 31.

[3] Мосин О.В., Игнатов И. // Интернет-журнал „НАУКОВЕДЕНИЕ“'. 2013. № 3.

[4] Френкель Я.И. Кинетическая теория жидкостей. Л.: Наука, 1975. $592 \mathrm{c}$.

[5] Maheshwary S., Patel N., Sathyamurthy N., Kulkarni A.D., Garde S.R. // J. Phys. Chem. A. 2001. V. 105. N 46. P. 10525.

[6] Хентов В.Я., Шачнева Е.Ю. Физико-химические процессы в техносфере. Учебное пособие. М.: РУСАЙНС, 2016. $36 \mathrm{c}$.

[7] Савостикова О.Н., Стехин А.А., Яковлева Г.В., Михайлова Р.И., Кирьянова Л.Ф. // Гигиена и санитария. 2007. № 6. С. 46.

[8] Белянчиков М.А., Горелик В.С., Горшунов Б.П., Пятышев А.Ю. // Кристаллография. 2017. Т. 62. № 2. C. 278; Belyanchikov M.A., Gorelik V.S., Gorshunov B.P., Pyatyshev A.Yu. // Crystallography. 2017. V. 62. N 2. P. 278.

[9] Downesand A., Elfick A. // J. Sensors. 2010. V. 10. N 3. P. 1871.

[10] Sikirzhytski V., Virkler K., Lednev I.K. // J. Sensors. 2010. V. 10. N 4. P. 2869.

[11] Walrafen G.E. // J. Chem. Phys. 1964. V. 40. P. 3249.

[12] Мосин О.В., Игнатов И. // Вода и водоочистные технологии. 2013. № 2. С. 12.

[13] Деулин Б.И. // Известия Волгоградского гос. техн. ун-та. 2008. T. 9. № 47. С. 70.

[14] Carey D.M., Korenowski G.M. // J. Chem. Phys. 1998. V. 108. N 7. P. 2669.

[15] Brysev A., Bunkin A., Klopotov R., Krutyanskii L., Nurmatov A., Perchin S. // Opt. Spectrosc. 2002. V. 93. N 2. P. 282.

[16] Perchin S. // Opt. Spectrosc. 2004. V. 96. N 2. P. 811.

[17] Burikov S., Dolenko T., Fadeev V. // Research Lett. in Optics. 2008. V. 2008. N 2. P. 4.

[18] Hafizi B., Palastro J.P., Penano J.R., Gordon D.F., Jones T.G., Helle M.H., Kaganovich D. // Opt. Lett. 2015. V. 40. Iss. 7. P. 1556.

[19] Rahn O., Maier M., Kaiser W. // Opt. Commun. 1969. V. 1. P. 109.

[20] Gorelik V.S. // J. Russian Laser Research. 1999. V. 20. P. 152.

[21] Gorelik V.S., Kudryavtseva A.D., Orlovich V.A., Tcherniega N.V., Vodchits A.I., Voinov Yu.P. // Nonlinear Phenomena in Complex Systems. 2012. V. 15. P. 360.

[22] Горелик В.С., Свербиль П.П. // Оптическая спектроскопия и стандарты частоты. Молекулярная спектроскопия. / Под ред. Синица Л.Н., Виноградов Е.А. 2004. С. 85. 
[23] Водчии А.И., Войнов Ю.П., Горелик В.С., Кудрявцева А.Д., Орлович В.А., Чернега Н.В. // Краткие сообщения по физике. 2013. Т. 40. № 12. С. 3; Vodchits A.I., Voinov Yu.P., Gorelik V.S., Kudryavtseva A.D., Orlovich V.A., Tcherniega N.V. // Bulletin of the Lebedev Physics Institute. 2013. V. 40. N 12. P. 329.

[24] Workman Jr.J., Weyer L. Practical Guide and Spectral Atlas for Interpretive Near-infrared Spectroscopy. London: Taylor and Francis Group, 2013. 320 p.

[25] Li Z., Li Z., Zhou M., Wang Y., Men Z., Sun C. // Opt. Lett. 2012. V. 37. P. 1319.

[26] Penzkofer A., Beidoun A., Lehmeir H.J. // Opt. and Quant. Electron. 1993. V. 25. P. 317.

[27] Защепина Г.Н. Свойства и структура воды. М.: Изд-во МГУ, 1974. 168 c. 